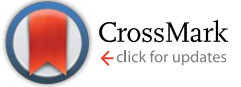

Cite this: RSC Adv., 2017, 7, 2880

Received 19th October 2016 Accepted 21st November 2016

DOI: $10.1039 / c 6 r a 25464 \mathrm{k}$

www.rsc.org/advances

\section{Novel synthesis of dual-suspended architectures between Si-pillars for enhanced photocatalytic performance $\dagger$}

\author{
Yu Sun,,$^{\mathrm{a}}$ Rui Chen,,$^{\mathrm{b}}$ Jihyeon Oh, ${ }^{\mathrm{a}}$ Bongyoung Yoo*a and Haiwon Lee*b
}

A facile approach is developed to synthesize a dual-suspended architecture, in which 3D carbon nanotube (CNT) networks are first bridged between Si pillars through a catalyzed method and suspended oxide architectures are subsequently synthesized on CNT networks through pulse electrodeposition. These dual-suspended structures show excellent photocatalytic activity toward methylene blue (MB) photodecomposition under visible light illumination.
Metal oxides are the most widely used materials in sensors, environmental pollution control, and energy conversion and storage. ${ }^{1-8}$ Among metal oxides, $\mathrm{Cu}_{2} \mathrm{O}$ has attracted a lot of attention as it is inexpensive, plentiful, environmentally friendly, and readily available. Furthermore, $\mathrm{Cu}_{2} \mathrm{O}$ is a p-type semiconductor with a direct bandgap of $2.0-2.2 \mathrm{eV}$, which has been studied previously for applications in solar energy converting devices, antifouling coatings, water splitting, and other photocatalytic reactions. ${ }^{9-15}$ It was documented that the catalytic abilities of catalysts are strongly influenced by surface electronic structures, which partially rely on their morphologies and exposed surface area. In our previous work, we electrochemically deposited $\mathrm{Cu}_{2} \mathrm{O}$ on $\mathrm{Ti} / \mathrm{Au} / \mathrm{Si}$ wafer substrates as photocatalysts. ${ }^{16}$ However, the photocatalytic abilities were limited due to the insufficient exposure of photocatalysts. Therefore, we hypothesised that the growth of suspended $\mathrm{Cu}_{2} \mathrm{O}$ would significantly increase the exposed surface area of catalysts and further enhance the catalytic properties.

Previously, numerous different kinds of materials have been studied to produce artificial networks. Among these materials, CNTs are considered as the most suitable candidates because of their excellent chemical, mechanical, and electrical properties. ${ }^{17-19}$ Therefore, in this work, CNT networks were employed as nano-substrates, on which the preparation of metal oxide architectures was carried out through pulse electrodeposition, forming dual-suspended architectures for enhanced photocatalytic performance.

${ }^{a}$ Department of Materials Engineering, Hanyang University, Ansan, Gyeonggi-do, 15588, Korea. E-mail: byyoo@hanyang.ac.kr

${ }^{b}$ Department of Chemistry, Hanyang University, Seoul, 04763, Korea. E-mail: haiwon@hanyang.ac.kr

$\dagger$ Electronic supplementary information (ESI) available. See DOI: 10.1039/c6ra25464k

\$Y. Sun and R. Chen contributed equally to this work.
As illustrated in Scheme 1, we first fabricated CNT networks as bridging materials for the growth of a suspended metal oxide architecture between Si pillars (abbreviated to $\mathrm{Si}_{\mathrm{P}}$ ) using a lowpressure thermal chemical vapor deposition (LPTCVD) method ${ }^{20,21}$ (abbreviated CNT-Si ${ }_{\mathrm{P}}$ ). Then, $\mathrm{Cu}_{2} \mathrm{O}$ was pulse electrodeposited by using $\mathrm{CNT}-\mathrm{Si}_{\mathrm{P}}$ as a working electrode, as described in a previous report. ${ }^{22-24}$ The details are shown in the ESI. $\dagger$ As shown in Fig. 1(A), CNT networks were massively synthesized between Si pillars. CNTs were also found around each Si pillar as the CNT growth started on the Si pillar substrates. TEM images of CNTs further confirmed the successful synthesis of carbon nanotube structures with an average width of $\sim 14 \mathrm{~nm}$, as shown in Fig. 1(B) and (C). To prepare a suspended $\mathrm{Cu}_{2} \mathrm{O}$ architecture on CNT networks (abbreviated $\mathrm{Cu}-\mathrm{CNT}-\mathrm{Si}_{\mathrm{P}}$ ), pulse electrodeposition was carried out by taking $\mathrm{CNT}-\mathrm{Si}_{\mathrm{P}}$ as a working electrode in a mixed solution containing $0.01 \mathrm{M}$ cupric acetate and $0.1 \mathrm{M}$ sodium acetate. As shown in Fig. 1(D), a large quantity of octahedral and quasioctahedral structures penetrated by CNTs was successfully synthesized. The high-magnification SEM image (Fig. 1(E)) and TEM image (Fig. 1(F)) indicate that the average size of the diagonal line of (quasi-)octahedron structures was $\sim 100-$ $200 \mathrm{~nm}$. The elemental mapping analysis suggested the presence of $\mathrm{Cu}$ (Fig. 1(G)) and $\mathrm{O}$ (Fig. 1(H)) components in the suspended (quasi-)octahedral structures. Interestingly, we

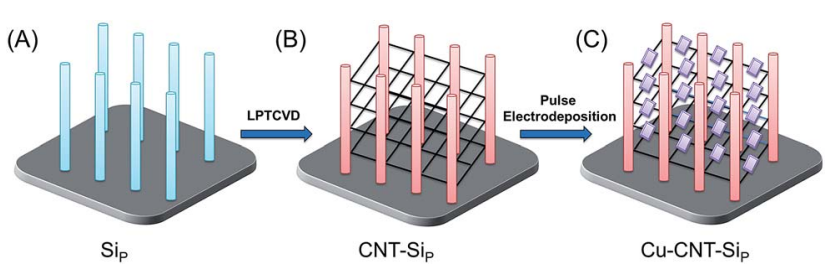

Scheme 1 Graphic illustration of each step for the preparation of suspended cuprous oxide $\left(\mathrm{Cu}_{2} \mathrm{O}\right)$ architecture. 


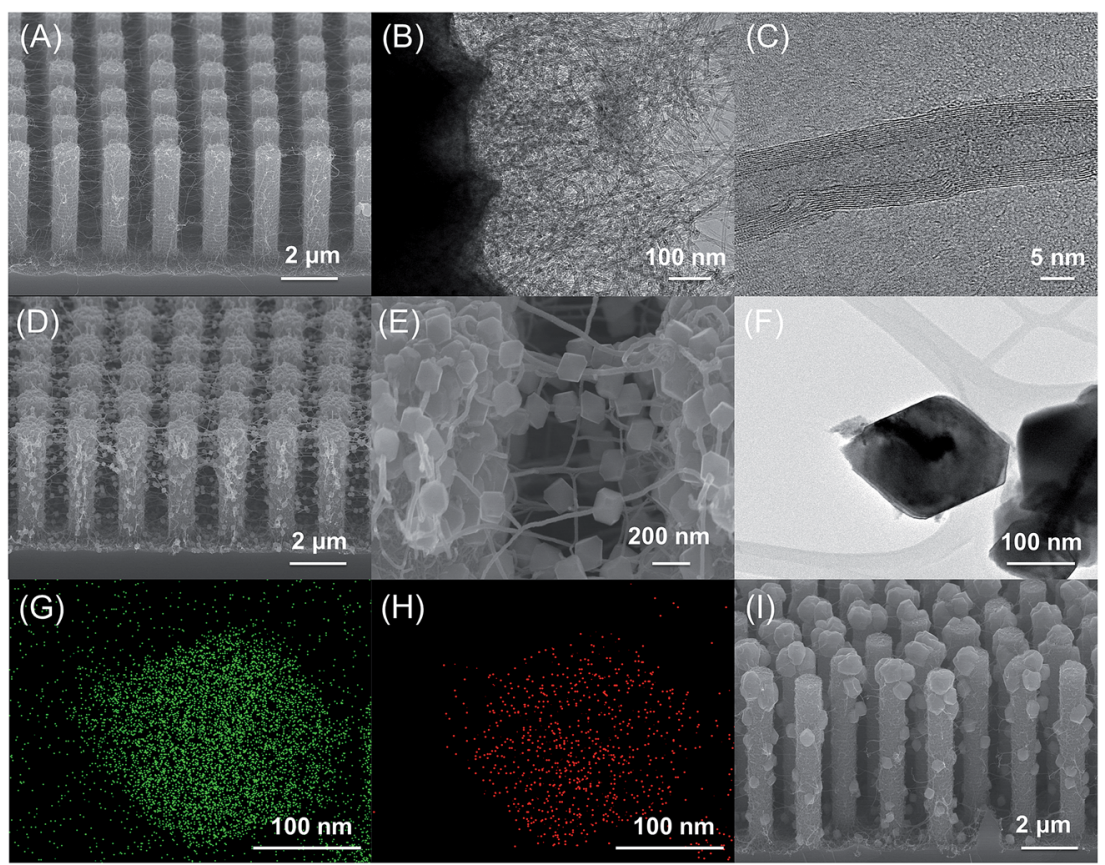

Fig. 1 SEM image of CNT-Si $(A)$ and TEM images of CNTs ((B), low magnification; (C), high magnification); SEM images ((D), low magnification; (E) high magnification) of $\mathrm{Cu}-\mathrm{CNT}-\mathrm{Si}_{\mathrm{p}}$; TEM image of suspended (quasi-)octahedron structures (F); TEM elemental mapping images of $\mathrm{Cu}$ (G) and $\mathrm{O}(\mathrm{H})$; SEM image of a failed $\mathrm{Cu}-\mathrm{CNT}-\mathrm{Si}_{\mathrm{p}}$ sample made by using highly-doped Si pillar substrates (I).

found that the successful synthesis of suspended architecture on CNT networks through pulse electrodeposition probably relies on the electrical conductivity of the Si-pillar substrate. When we used highly-doped Si-pillar samples, a large amount of oxides was formed on the top of the Si pillar (Fig. 1(I)), and only a trace amount of suspended architectures was synthesized on the CNT networks.

To identify the microstructure of suspended (quasi-)octahedron structures, X-ray diffraction (XRD) measurements were carried out for all samples. As shown in Fig. 2(A), diffraction peaks of the $\mathrm{Cu}-\mathrm{CNT}-\mathrm{Si}_{\mathrm{P}}$ sample (blue line) at $2 \theta=36.8,42.1$, and 61.2 were not observed for $\mathrm{Si}_{\mathrm{P}}$ (black line) or $\mathrm{CNT}-\mathrm{Si}_{\mathrm{P}}$ (red line) samples. These diffraction peaks can be indexed to face centered cubic phase $\mathrm{Cu}_{2} \mathrm{O}$ (JCPDS 77-0199), ${ }^{25}$ which confirmed that the suspended (quasi-)octahedron structures mainly composed of cuprous oxides. Furthermore, additional diffraction peaks were observed at $2 \theta=32.4$ and 38.6, which probably belong to either $\mathrm{CuO}$ or $\mathrm{Cu}(\mathrm{OH})_{2}$.
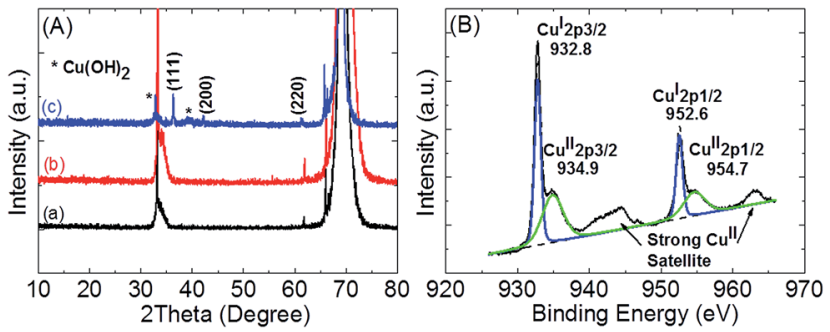

Fig. 2 (A) X-ray diffraction patterns of (a) $\mathrm{Si}_{p},(\mathrm{~b}) \mathrm{CNT}-\mathrm{Si}_{\mathrm{p}}$, and (c) $\mathrm{Cu}-$ CNT-Si ; (B) XPS analysis of Cu element for $\mathrm{Cu}-\mathrm{CNT}-\mathrm{Si}_{\mathrm{p}}$ immediately after preparation.
It has been reported that $\mathrm{Cu}_{2} \mathrm{O}$ (rather than $\mathrm{CuO}$ ) can be synthesized under our employed conditions. ${ }^{24,26}$ Nevertheless, $\mathrm{Cu}(\mathrm{OH})_{2}$ is normally synthesized as a side product when changing the electrodeposition potential. ${ }^{27}$ Therefore, further confirmation of the composition was conducted using X-ray photoelectron spectroscopy (XPS). As shown in Fig. 2(B), a sharp and symmetric XPS peak, which corresponded to the $\mathrm{Cu}^{\mathrm{I}} 2 \mathrm{p}_{3 / 2}$ of $\mathrm{Cu}_{2} \mathrm{O}$, was observed at $932.8 \mathrm{eV}$. A shoulder peak at $934.9 \mathrm{eV}$ corresponding to $\mathrm{Cu}^{\mathrm{II}} 2 \mathrm{p}_{3 / 2}$ of $\mathrm{Cu}(\mathrm{OH})_{2}$ together with strong $\mathrm{Cu}^{\mathrm{II}}$ satellite peaks were also clearly observed, indicating that additional XRD peaks actually came from $\mathrm{Cu}(\mathrm{OH})_{2}$ instead of $\mathrm{CuO}$ because the $\mathrm{Cu}^{\mathrm{II}} 2 \mathrm{p}_{3 / 2}$ peak of $\mathrm{CuO}$ is normally located at $\sim 933.4 \mathrm{eV}$. To confirm the stability of $\mathrm{Cu}-\mathrm{CNT}-\mathrm{Si}_{\mathrm{P}}$, we placed our samples in air for 1 month without any treatment and carried out XPS measurements. As shown in Fig. S2, $\uparrow$ no significant difference was found when comparing XPS data with those measured for as-prepared samples. These results revealed that our samples have good stability in air, and that no $\mathrm{CuO}$ was formed either during the electrodeposition process or upon exposure to air.

Furthermore, these 3D hierarchical networks were investigated using Raman spectroscopy to understand the formation of CNTs around the patterned Si pillars and the formation of suspended metal oxide architectures on CNTs networks. As shown in Fig. 3(A), the Raman spectra of CNT-Si $i_{P}$ showed two unique Raman bands at $\sim 1350$ and $1590 \mathrm{~cm}^{-1}$, which were in good agreement with the well-known $\mathrm{D}$ and $\mathrm{G}$ bands of typical CNTs, respectively. ${ }^{17-19}$ These results indicate that the initial nano-networks were constructed of CNTs bridging between $\mathrm{Si}$ pillars. After the electrochemical synthesis of the suspended oxide architecture, both the D and G bands were significantly 

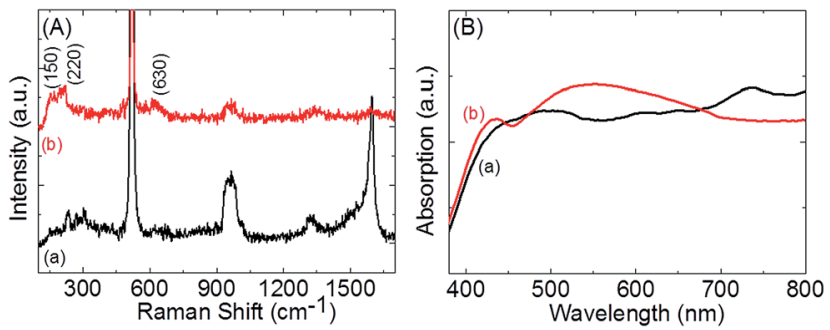

Fig. 3 (A) Raman spectra of (a) CNT-Sip and (b) $\mathrm{Cu}-\mathrm{CNT}-\mathrm{Si}_{\mathrm{p}}$; (B) UV-vis spectra of (a) CNT-Si $i_{p}$ and (b) $\mathrm{Cu}-\mathrm{CNT}-\mathrm{Si}_{\mathrm{p}}$.

weakened, but did not disappear. In a previous report, metal oxide-coated CNT networks were synthesized through an electrodeposition method, in which neither D nor G bands were detected after coating. ${ }^{27}$ This suggests that our approach provided a suspended oxide architecture instead of fully coated samples. Raman scattering is another useful tool to distinguish different oxide species. Group theoretical calculations have shown that $\mathrm{Cu}_{2} \mathrm{O}$ has six zone-center optical phonon modes. ${ }^{28-30}$ Unfortunately, the Raman-active mode $F_{2 g}$ at $520 \mathrm{~cm}^{-1}$ was covered by a strong Si Raman signal and therefore could not be visually distinguished. Two IR active modes $F_{1 u}$ at 150 and $630 \mathrm{~cm}^{-1}$ and overtone $2 \mathrm{E}_{\mathrm{u}}$ at $220 \mathrm{~cm}^{-1}$ were clearly observed. The mode at $415 \mathrm{~cm}^{-1}$ due to a multiphoton process was quite weak in our case. However, the characteristic optical phonon modes for $\mathrm{CuO}$ were not observed in our samples. ${ }^{31-33}$ These results, which are in accordance with XRD and XPS data, further confirmed that $\mathrm{Cu}_{2} \mathrm{O}$ was the dominant component in the suspended metal oxide architecture. Subsequently, UV-vis absorption spectra were measured for both $\mathrm{CNT}_{-} \mathrm{Si}_{\mathrm{P}}$ and $\mathrm{Cu}-$ $\mathrm{CNT}_{-} \mathrm{Si}_{\mathrm{P}}$ samples. These results clearly showed that the visible light absorption in the range of $450 \mathrm{~nm}$ to $680 \mathrm{~nm}$ was enhanced due to the formation of the suspended oxide architectures (Fig. 3(B)).

The photocatalytic degradation of MB dye as a function of time in the presence of $\mathrm{Cu}-\mathrm{CNT}-\mathrm{Si}_{\mathrm{P}}$ was determined by measuring the UV-vis absorption spectra (Fig. S3 (A)†). For a better comparison, MB decomposition was investigated with $\mathrm{Si}_{\mathrm{P}}$ (Fig. S3(B)广), CNT-Si $i_{\mathrm{P}}$ (Fig. S3(C) $\dagger$ ), and with a nonsuspended architecture (abbreviated as $\mathrm{Cu}-\mathrm{Si}_{\mathrm{P}}$, Fig. $\mathrm{S3}(\mathrm{D}) \dagger$ ). Details related to the preparation of $\mathrm{Cu}-\mathrm{Si}_{\mathrm{P}}$ are shown in the ESI. $\dagger$ The photocatalytic reaction of the MB dye was performed by putting our sample in $\mathrm{MB}$ dye solution (10 ppm) under visible light illumination for $2 \mathrm{~h}$. Before light illumination, samples were kept in the MB solution for $1 \mathrm{~h}$ in the dark to reach adsorption equilibrium. We found that both $\mathrm{Si}_{\mathrm{P}}$ and $\mathrm{CNT}_{\mathrm{Si}} \mathrm{i}_{\mathrm{P}}$ had weak photocatalytic abilities towards MB decomposition under visible light illumination. However, the latter had better adsorption ability, probably due to the formation of $\mathrm{CNT}$ networks. In contrast, both $\mathrm{Cu}-\mathrm{Si}_{\mathrm{P}}$ and $\mathrm{Cu}-\mathrm{CNT}-\mathrm{Si}_{\mathrm{P}}$ presented a gradual and steady decrease in the absorption peak formed at $\lambda_{\max }=664 \mathrm{~nm}$. The percentage of dye degradation, $\eta$, was calculated as follows:

$$
\eta=\frac{A_{0}-A}{A_{0}} \times 100 \%
$$

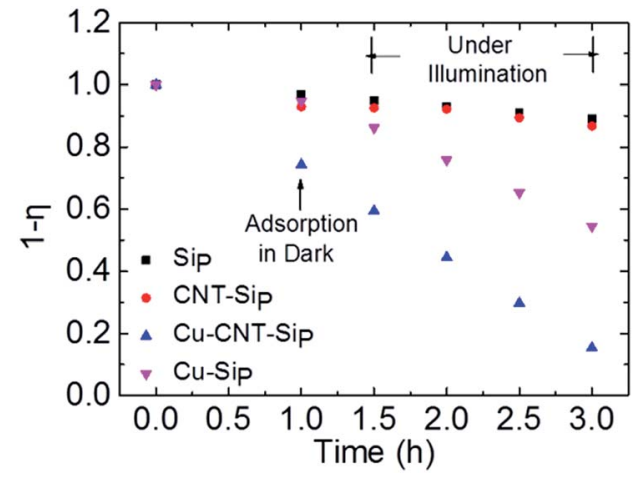

Fig. 4 Comparison of photocatalytic decomposition of $\mathrm{MB}$ with $\mathrm{Si}_{\mathrm{p}}$ (black, - $)$, CNT-Sip (red, - ), Cu-CNT-Sip (blue, $\mathbf{\Delta}$ ), and Cu-Sip (pink, V) as photocatalysts under visible light irradiation within $2 \mathrm{~h}$. Data for the dye residue after $1 \mathrm{~h}$ adsorption equilibrium in dark are included.

where $A_{0}$ is the initial absorbance of the dye, and $A$ is the timedependent absorbance.

To visually compare the photocatalytic properties, the percentage of dye residue $(1-\eta)$ was plotted against the reaction time (Fig. 4). The value of $(1-\eta)$ after $1 \mathrm{~h}$ of adsorption equilibrium in the dark was calculated for all samples. These results showed that our suspended oxide architecture $(\mathrm{Cu}-$ $\mathrm{CNT}-\mathrm{Si}_{\mathrm{P}}$ ) had a strong adsorption ability, in that $28 \%$ of MB dye was removed within $1 \mathrm{~h}$. After $2 \mathrm{~h}$ of photocatalytic reactions, no significant $\mathrm{MB}$ degradation was observed for $\mathrm{Si}_{\mathrm{P}}$ and $\mathrm{CNT}-\mathrm{Si}_{\mathrm{P}}$, and only $46 \%$ of the MB dye was totally removed by $\mathrm{Cu}-\mathrm{Si}_{\mathrm{p}}$. However, $\mathrm{Cu}-\mathrm{CNT}-\mathrm{Si}_{\mathrm{P}}$ with suspended metal oxide architectures was extremely effective for MB decomposition, removing a total of $86 \%$ of the $\mathrm{MB}$ after $2 \mathrm{~h}$ of the photocatalytic reaction.

We provided the first demonstration of a facile approach to synthesize a dual-suspended architecture. The CNT network that bridges between patterned Si pillars was first synthesized by LPTCVD. Nanometer-sized octahedron and quasioctahedron structures of cuprous oxide were synthesized on CNT networks through pulse electrodeposition, as confirmed by XRD, XPS, and Raman spectroscopy. The as-synthesized samples, $\mathrm{Cu}-\mathrm{CNT}-\mathrm{Si}_{\mathrm{p}}$, showed excellent photocatalytic abilities towards $\mathrm{MB}$ decomposition under visible light illumination, and $86 \%$ of MB dye was removed within $2 \mathrm{~h}$. To the best of our knowledge, the controlled synthesis of suspended architectures on suspended substrates (here, CNT networks) by the electrodeposition process has seldom been documented. Our findings offered a facile and rational method for the designed synthesis of dual-suspended architectures. However, we believe that an investigation of the associated growth mechanisms can facilitate a deep understanding of designed materials synthesis, which will be a focus of the follow-up experiments.

\section{Acknowledgements}

The authors thank the National Research Foundation of Korea and Ministry of Science, ICT and Future Planning for financial support (2012M3A7B4035286，2012R1A6A1029029，2015R1A5A1037548, 2016K1A4A3914691 and IITP2016R0992161021). Yu Sun and Rui Chen contributed equally to this work. 


\section{References}

1 A. S. Arico, P. Bruce, B. Scrosati, J. M. Tarascon and W. Van Schalkwijk, Nat. Mater., 2005, 4, 366-377.

2 Y. G. Guo, J. S. Hu and L. J. Wan, Adv. Mater., 2008, 20, 28782887.

3 M. C. Toroker and E. A. Carter, J. Mater. Chem. A, 2013, 1, 2474-2484.

4 Y. Sekine, Atmos. Environ., 2002, 36, 5543-5547.

5 M. Miyauchi, A. K. Nakajima, T. Watanabe and K. Hashimoto, Chem. Mater., 2002, 14, 4714-4720.

6 N. Talebian and M. R. Nilforoushan, Thin Solid Films, 2010, 518, 2210-2215.

7 H. Meixner, J. Gerblinger, U. Lampe and M. Fleischer, Sens. Actuators, B, 1995, 23, 119-125.

8 N. Barsan, D. Koziej and U. Weimar, Sens. Actuators, B, 2007, 121, 18-35.

9 B. P. Rai, Sol. Cells, 1988, 25, 265-272.

10 L. C. Olsen, F. W. Addis and W. Miller, Sol. Cells, 1982, 7, 247-279.

11 S. Kiil, K. Dam-Johansen, C. E. Weinell, M. S. Pedersen and S. A. Codolar, Biofouling, 2003, 19, 37-43.

12 S. Kiil and K. Dam-Johansen, Prog. Org. Coat., 2007, 60, 238247.

13 P. E. de Jongh, D. Vanmaekelbergh and J. J. Kelly, Chem. Commun., 1999, 1069-1070, DOI: 10.1039/a901232j.

14 M. Hara, T. Kondo, M. Komoda, S. Ikeda, K. Shinohara, A. Tanaka, J. N. Kondo and K. Domen, Chem. Commun., 1998, 357-358, DOI: 10.1039/a707440i.

15 Z. K. Zheng, B. B. Huang, Z. Y. Wang, M. Guo, X. Y. Qin, X. Y. Zhang, P. Wang and Y. Dai, J. Phys. Chem. C, 2009, 113, 14448-14453.

16 S. Yoon, M. Kim, I. S. Kim, J. H. Lim and B. Yoo, J. Mater. Chem. A, 2014, 2, 11621-11627.

17 S. F. Zheng, J. S. Hu, L. S. Zhong, W. G. Song, L. J. Wan and Y. G. Guo, Chem. Mater., 2008, 20, 3617-3622.
18 B. You, L. L. Wang, L. Yao and J. Yang, Chem. Commun., 2013, 49, 5016-5018.

19 E. Unger, G. S. Duesberg, M. Liebau, A. P. Graham, R. Seidel, F. Kreupl and W. Hoenlein, Appl. Phys. A: Mater. Sci. Process., 2003, 77, 735-738.

20 J. Seo, T. J. Lee, S. Ko, H. Yeo, S. Kim, T. Noh, S. Song, M. M. Sung and H. Lee, Adv. Mater., 2012, 24, 1975-1979.

21 J. Seo, T. J. Lee, C. Lim, S. Lee, C. Rui, D. Ann, S. B. Lee and H. Lee, Small, 2015, 11, 2990-2994.

22 L. K. Tsui, L. L. Wu, N. Swami and G. Zangari, ECS Electrochem. Lett., 2012, 1, D15-D19.

23 S. Tao and D. Y. Li, Nanotechnology, 2006, 17, 65-78.

24 Y. E. Gu, X. Su, Y. L. Du and C. M. Wang, Appl. Surf. Sci., 2010, 256, 5862-5866.

25 S. Kumar, C. M. A. Parlett, M. A. Isaacs, D. V. Jowett, R. E. Douthwaite, M. C. R. Cockett and A. F. Lee, Appl. Catal., B, 2016, 189, 226-232.

26 N. Fredj and T. D. Burleigh, J. Electrochem. Soc., 2011, 158, C104-C110.

27 K. G. Lee, S. Lee, S. J. Chang, B. G. Choi, J. Seo, A. Sangalang, D. H. Kim, T. J. Park, M. K. Lee, S. J. Lee and H. Lee, Small, 2015, 11, 4292-4297.

28 A. Singhal, M. R. Pai, R. Rao, K. T. Pillai, I. Lieberwirth and A. K. Tyagi, Eur. J. Inorg. Chem., 2013, 2640-2651, DOI: 10.1002/ejic.201201382.

29 K. Huang, Z. Phys., 1963, 171, 213-225.

30 P. Dawson, M. M. Hargreave and G. R. Wilkinson, J. Phys. Chem. Solids, 1973, 34, 2201-2208.

31 W. Z. Wang, L. J. Wang, H. L. Shi and Y. J. Liang, CrystEngComm, 2012, 14, 5914-5922.

32 J. F. Xu, W. Ji, Z. X. Shen, W. S. Li, S. H. Tang, X. R. Ye, D. Z. Jia and X. Q. Xin, J. Raman Spectrosc., 1999, 30, 413-415.

33 W. Z. Wang, Q. Zhou, X. M. Fei, Y. B. He, P. C. Zhang, G. L. Zhang, L. Peng and W. J. Xie, CrystEngComm, 2010, 12, 2232-2237. 